\title{
5. Collapsus, or how to make players become ecological citizens
}

\author{
Joost Raessens
}

\begin{abstract}
Contemporary games are increasingly used to make a difference at an individual, community, and/or societal level. Ecological games are one kind of such 'games for change': they seek to contribute to ecological thought and turn players into ecological citizens. This chapter draws inspiration from the conceptual framework of psychologist Stoknes. He theorizes the 'psychological climate paradox': the fact that although climate science facts are becoming more solidly documented and disturbing every year, most people either do not believe in these facts or do not act upon them. This chapter discusses how Collapsus - Energy Risk Conspiracy (Palotta 2010) might contribute to solving the paradox by making people reflect on the global, political, and cultural implications of climate change and act accordingly.
\end{abstract}

Keywords: Climate communication, ecological citizenship, games for change, psychological climate paradox

When I say, 'Optimism is a duty,' this means not only that the future is open but that we all help to decide it through what we do. We are all jointly responsible for what is to come. So we all have a duty, instead of predicting something bad, to support the things that may lead to a better future. Popper (1999, 143-144)

Contemporary digital games are increasingly used not only to entertain, but also to persuade people, raising their awareness and changing or reinforcing their attitudes and behavior for the good of society. Ecological games belong to this category of 'persuasive games' (Jacobs 2017; Jacobs, Jansz, and De

Glas, R., S. Lammes, M. de Lange, J. Raessens, and I. de Vries, eds. 2019. The Playful Citizen. Civic Engagement in a Mediatized Culture. Amsterdam: Amsterdam University Press. DOI: $10.5117 / 9789462984523 / \mathrm{CHO} 5$ 
la Hera 2017). They seek not only to contribute to ecological thought, but also “to make' people become ecological citizens" (MacGregor 2014, 120). In the last few years, digital games have encouraged support, sympathy, and action for a variety of ecological issues. ${ }^{1}$ In this chapter, I examine how Collapsus - Energy Risk Conspiracy (Pallotta 2010) frames the immanent energy transition from fossil fuels to alternative energy sources. ${ }^{2}$ My analysis aims to offer a conceptual clarification of the rhetorical (textual) strategies that a 'gamelike' production such as Collapsus uses to raise awareness about the issue of energy transition. I use the word 'rhetorical' here in the sense of a persuasive discourse "adopted by members of a particular affiliation to persuade others of the veracity and worthwhileness of their beliefs" (Sutton-Smith 1997, 8). My investigation draws inspiration from the conceptual framework of psychologist and economist Per Espen Stoknes, who theorizes what I would call one of the most pressing issues within the field of climate change communication, the 'psychological climate paradox': the fact that "climate science facts are getting more solidly documented and disturbing every year," while "most people either don't believe in or do not act upon those facts" $(2015,3)$. Though Stoknes provides a productive framework for understanding and overcoming the obstacles of conventional climate communication strategies, his set of recommendations remains very general. By analysing the empirical building blocks of Collapsus, I will develop Stoknes' framework further in order to turn it into a strategic toolkit for civic action that can be used in the domain of playful ecological communication. In the first section, I will briefly introduce Collapsus and discuss how Stoknes defines the psychological climate paradox and how he envisions solving it. In the second section, I will further develop and theorize some of his strategies. In the third section, I will discuss in detail if, and if so how, Collapsus might contribute to solving the paradox by making people reflect on the global and political implications of the energy transition and act accordingly. I present my conclusions in the last section.

1 For an overview of recent examples of environmental games, see the Games for Change $\left(\mathrm{G}_{4} \mathrm{C}\right)$ website, where we find its mission statement to be "catalyzing social impact through digital games" (G4C 2018). Also see Raessens $(2017,2018)$.

2 Collapsus was commissioned by the Dutch broadcasting company VPRO and produced by Amsterdam-based company Submarine Channel. It can be played at collapsus.com. Collapsus is an important case to discuss because it succeeded - back in 2010 - in imagining the social and political implications of global warming in an innovative way. It was aimed at a predominantly younger and connected generation. Statistics show that it is difficult for documentary films to reach young audiences; only 18-20 per cent is younger than 34 years old. Collapsus reached 41 per cent of that age category. 


\section{The psychological climate paradox and how to solve it}

The 'psychological climate paradox' that Stoknes is referring to-the more climate science facts you hear, the less likely you are to take action-is only an apparent paradox. It might be solved once it becomes clear, for example, that strategies other than presenting 'facts only' might indeed convince people to change their behavior regarding ecological issues. The persuasive argument in a documentary like An Inconvenient Truth (Guggenheim 2006) is primarily based on factual evidence about global warming. Former United States vice president $\mathrm{Al}$ Gore sketches a doom scenario, as its title already indicates, suggesting only at the end of the film that the climate crisis might be solved and how this might be achieved. This Changes Everything (Lewis 2015), a documentary inspired by Naomi Klein's book of the same name, on the other hand, frames global warming as an opportunity to build a better world. It does so by presenting compelling stories of communities all around the world that are resisting our 'failed' economic system and supporting environmentalism.

Another example of such a compelling story is Collapsus - Energy Risk Conspiracy (Pallotta 2010). Collapsus is an online production that engages users with realistic future scenarios (2012-2025) about anticipated energy crises and the necessity of transitioning from fossil fuels to alternative energy sources. This interactive experience consists of three screens or panels contained on one web page (for the three-panel structure, see Figure 5.1): it merges a fictional storyline via live action and animated graphics, with minigames (both presented in the center panel), documentary clips (right panel) and simulation games (left panel).

Collapsus is usually presented as a game. The Games for Change website, for example, refers to Collapsus in their list of environmental games. Submarine Channel, the production studio behind Collapsus, also includes Collapsus under the category of 'games.' We can use the five shared characteristics of games - they are goal oriented; the player has to follow specific rules; the system provides some kind of feedback; often there is a competition element; and participation is voluntary (Jansz 2016) — to understand the 'gameness' of Collapsus. The overall goal of Collapsus is to play it until the end while unlocking all the information made available by the three panels. More specifically, you have to win the minigames to reveal specific information, and win the simulation games by producing enough sustainable energy to meet the rising demand. One important rule is that you have to unlock the information when it becomes available in the different panels. You can cheat by skipping the minigames, for example, but then you would fail to understand some important aspects of the story; the system provides the player with feedback during the minigames and sim games. You do not 


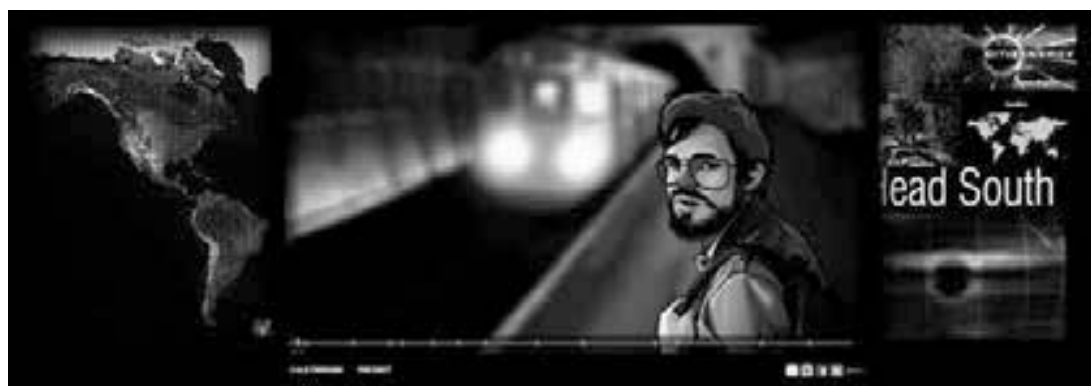

5.1: Collapsus - Three-panel structure.

compete with other players, but you do compete with the game's system. And you decide yourself whether to play or not.

From the perspective of 'mediality,' Collapsus can be seen as multi-medial, because it combines multiple media forms, or transmedial, because the media forms are complementary. But I would prefer to identify it as an intermedial production because the media forms in the different panels interact with each other. As Chiel Kattenbelt points out, intermediality results "in a redefinition of the media that are influencing each other, which in turn leads to a refreshed perception" (2008, 25).

If we want to answer the question if, and if so how, Collapsus can be used to engage individual citizens in the issue of energy transition, we first need to improve our understanding of the reasons why conventional climate communication does not always work optimally, or, worse still, works counter-productively (erecting barriers). Moreover, we need to know what we should do to overcome these barriers (solutions) and what concrete strategies we should use to make communication work (strategies), see Table $1 .^{3}$

Table 1: Barriers, solutions, and strategies

\begin{tabular}{|c|c|c|}
\hline $\begin{array}{l}\text { Barriers } \\
\text { (first section of this chapter) }\end{array}$ & $\begin{array}{l}\text { Solutions } \\
\text { (first section of this chapter) }\end{array}$ & $\begin{array}{l}\text { Strategies } \\
\text { (second section of this chapter) }\end{array}$ \\
\hline distant in space and time & $\begin{array}{l}\text { close, human, personal, } \\
\text { urgent }\end{array}$ & $\begin{array}{l}\text { * moral ideas: progressive, } \\
\text { optimistic }\end{array}$ \\
\hline doom scenario & opportunities, hope & $\begin{array}{l}\text { * persuasion: narratives, } \\
\text { documentaries, games }\end{array}$ \\
\hline $\begin{array}{l}\text { not compatible with } \\
\text { our values }\end{array}$ & in line with our values & $\begin{array}{l}\text { * social networks: many-to- } \\
\text { many communication } \\
\text { * citizenship: post-liberal, global }\end{array}$ \\
\hline
\end{tabular}

3 For a summary of Stoknes' argument, see his chapter 'From barriers to solutions' (2015, 87-94). I present my own interpretation of his argument in Table 1. 
Three barriers might cause conventional climate communication to lead to a state of denial. The first barrier arises when global warming is framed as being distant in space and time. For the majority of us living in the West, the impact of global warming is still relatively far away, both in time and space. That is why Rob Nixon refers to climate change as 'slow violence.' He writes it is "a violence that occurs gradually and out of sight, a violence of delayed destruction that is dispersed across time and space, an attritional violence that is typically not viewed as violence at all" $(2011,2) \cdot{ }^{4}$ For example, research shows that only a minority of the Dutch population believe that fossil fuels have a significant impact on the climate; and only a very small minority see energy transition as an urgent challenge, especially when compared with issues such as the economy and migration (SCP 2016). The second barrier arises when global warming is framed as a doom scenario, an apocalyptic-movie mode without any thinkable practical solutions, which is depressing and generates the desire to avoid the topic altogether. Energy transition is indeed not uppermost in the Dutch mind (Ibid.). The third barrier arises when global warming is framed in such a way that it is not compatible with our values or our sense of identity. Dutch citizens, for example, are interested in the transition to other energy sources, not so much because of climate change, but because they like the idea of being energy independent; they want the stable delivery of energy and support the potential economic growth that results from such a transition (Ibid.).

In order to make climate communication productive, we need to turn these three barriers into solutions. First, climate change must be framed as being close, human, personal, and urgent. One possible way of doing this-as Collapsus does-is to link the subject (energy transition) to violent events taking place in the here and now of the story world. As a result, the energy transition is experienced by the characters and, hopefully, the players as "immediate in time, explosive and spectacular in space, and as erupting into instant sensational visibility" (Nixon 2011, 2). Second, climate messages must be framed in a positive, hopeful way, providing opportunities for consistent and visible action. As we will see later, Collapsus combines an alarming message with a variety of hopeful opportunities through different scenarios of civic engagement. Third, climate change must be framed in such a way that the solutions are in line with our values. That is, as long

4 This is, of course, not the case for those communities that are directly threatened by global warming (Lewis 2015), "particularly (though not exclusively) across the so-called global South" (Nixon 2011, 4). The most visible impact of global warming in our everyday lives in the West is in extreme weather conditions, like heatwaves, hurricanes, droughts, wildfires, and floods. 
as they are not conflicting with the notion of environmentalism, as I will discuss in the next section. As I have discussed elsewhere, people 'play' their identity: people play their values, they play on the basis of who they are, how they understand themselves, the values they want to live by, and who and what they want to become (Raessens 2015). Collapsus tries to persuade its audience by presenting a variety of role models with different beliefs, values, and behaviors that the audience can identify with. For example, it links the necessity of energy transition with the notion of the stable delivery of energy and economic independence.

\section{Strategies for raising awareness}

On the basis of these three barriers with their corresponding solutions, I propose four complementary strategies to make climate communication more effective. The discourse around climate must mobilize and reinforce progressive and positive moral ideas; it must be persuasive, changing attitudes and behavior by using narratives, documentary information, and games; it must stimulate social learning by using the power of social networks; and it must stimulate a post-liberal and global form of citizenship.

Moral ideas: Progressive and optimistic. In order to increase our understanding of how Collapsus frames energy transition, it is productive to use Lakoff's distinction between conservative and progressive moral systems (e.g. Flanagan and Nissenbaum 2014). The two systems represent contrasting ideas about environmentalism, which is defined by Lakoff as follows: "The natural world is being destroyed and it is a moral imperative to preserve and reconstitute as much of it as possible as soon as possible" $(2010,80)$. Whereas the conservative system includes a number of ideas that work against environmentalism — such as nature being there for human use and exploitation, a let-the-market-decide ideology, and the idea that making a profit and economic growth are goals in themselves (Ibid., 74-75) - the progressive system includes various ideas that support environmentalism, such as empathy linking us with other beings and other things, responsibility for taking care of yourself and others, and the ethic of excellence calling on us to improve the environment (Ibid., 76). This is in line with Stoknes' argument: "We ought to [...] protect and compassionately care for ourselves, current and future generations, and the other beings we share the planet with" $(2015,118)$. One important thing Stoknes is adding here is that we need to reframe the climate message in such a way that the message is 
supported with hope, positive emotions, and opportunities. Collapsus, for example, presents progressive strategies for improving the environment via the transition from fossil fuels to solar and wind power.

Persuasion: Narratives, documentaries, and games. Collapsus tries to raise awareness about the difficult choices we all have to make in relation to the impending energy crisis. A better understanding and use of persuasive technology "will significantly expand the toolbox for climate communication" (Stoknes, 130). Because Collapsus combines a fictional storyline with documentaries and games, we need to analyze the persuasive rhetoric of these different media, not only separately, but also in their interconnectedness. The problem is that while strategies of persuasive rhetoric have been studied, the research has mainly considered these media forms in isolation. Think, for example, of the analysis of written, text-based media (Killingsworth and Palmer 1992) and image-based media (Dobrin and Morey 2009). To understand how persuasiveness is embedded in Collapsus' design, I will focus on the narratives it portrays (or allows the player to develop), the documentary information it presents, and the system and rules of the games it allows the users to play.

Narratives. In his study of persuasive games, Ruud Jacobs (2017) refers to the importance of character-based narrative persuasion. Research done on screen-based media in general, such as film, television, or games, shows that users' attitudes are more likely to change-leading, for example, to civic engagement - when the users identify with role models or protagonists who go through the same stages of change (on screen) as the users are supposed to (e.g. Slater 2002; Green and Jenkins 2014; Jenkins, Ito, and boyd 2016). Or, as Michael Ryan and Douglas Kellner put it: "The slow transformation of ordinary people into informed opponents of the corporate system probably appealed more to audiences than if the characters had begun as radicals" (Ingram 2000, 169). As we will see in more detail later, this form of social learning is what Collapsus aims to do. It wants to offer players the opportunity to identify with characters such as Vera and the changes she goes through in the various stages. Stoknes identifies three extra characteristics that storytelling should have in order to be able to convince people of the necessity of environmentalism. First, narratives must foster creativity: "There must be room for humour, emotion, visualization, point of view, climax, surprise, plot, drama. Above all, make it personal and personified" (2014, 148). Second, there must be room for more than one narrative perspective: "I don't think there is just one right type of climate story to tell to get people to understand the urgency of the issue and move them to action. Rather, 
a plurality of stories is needed, each creating meaning and engagement for different groups of people" (Ibid., 132). Third, the stories must offer the possibility of some kind of feedback. Stoknes asks: "Can we really measure if we're changing in the right direction [...]?” (Ibid., 152). As we will see in more detail in the next section, this, again, is what Collapsus tries to do.

Documentaries. Collapsus not only provides accurate documentation of the imminent energy transition, but it is also a playful re-enactment of this event. To better understand the persuasive power of Collapsus as a whole, we can direct our attention to what documentary theorist Michael Renov calls "the four fundamental tendencies or rhetorical/aesthetic functions attributable to documentary practice," which are to express, to analyze or interrogate, to reveal, and to persuade or promote $(1993,21)$. These four discursive functions are indeed present in Collapsus' fictional storyline, news reports, minigames, and simulation games, albeit in different forms: the difficult choices we all have to make are expressed in the lives of the main characters within the fictional storyline; the geopolitical implications of the energy transition are analyzed and interrogated in the news reports; the complexity, the best solutions and a conspiracy are revealed in the minigames and simulation games. Collapsus uses these three functions-expression, analysis/interrogation, and revelation - in the end to promote a specific position in this debate, and to persuade users to adopt this point of view. ${ }^{5}$

Games. According to Ian Bogost (2007), persuasive games have the unique capability of employing what he calls 'procedural rhetoric' to address serious topics, such as global warming. The goal of a game-for example 'supporting environmentalism' - can be found in its formal system, more specifically in the properties of the rules. Players are presumed to surrender to the seduction of a game by interpreting the game as suggested and being guided by its rules. The idea that procedurality structures, helps facilitate, or has a (strong) impact on the game's interpretation seems to be a valid observation, but not to the extent that it 'determines' its meaning (Sicart 2011). Games, and this applies to Collapsus as a whole, are polysemic and therefore open to many readings. Players may activate three interpretative strategies as a reaction to what Sherry Turkle calls the "seduction of simulation" (1996, 71). They can either surrender to the seduction by interpreting it more or less according to the encoded ideological message (resignation); they may understand — and possibly oppose — a simulation by decoding the

5 For the argument that not only news reports but also fiction and games can be used as a documentary medium, see Raessens (2006). 
assumptions that are built into a medium (understanding); or they can completely disavow the social and political importance of these kinds of media (denial). In the case of Collapsus, simulation resignation seems to be the dominant reaction. ${ }^{6}$ Dutch film magazine $S k r i e n$, for example, calls Collapsus' combination of narratives, documentaries, and games a "trendsetter for the future [...] Collapsus takes place in the coming decades and confronts you with realistic [my italics] future scenarios about the expected global energy crisis" (De Crom 2010, 8-9; translation by the author).

Social networks: Many-to-many communication. Stoknes emphasizes the use of the power of social networks. This idea can help us to understand an important aspect of global warming communication. We should not only use one-to-many communication models (such as television documentaries), but also interactive many-to-many communication models (such as meetups, whether online or offline). This is because group behavior can be a powerful way to influence individual people's behavior: "Being part of an eco-network is one of the biggest determinants of pro-environmental behavior" (Stoknes 2014, 105). This is why, for example, Tegenlicht, a documentary series from the Dutch public broadcaster VPRO, ${ }^{7}$ and the cultural organization Pakhuis de Zwijger have been organizing regular meetups since 2013 that take place a few days after a particular television documentary has been broadcast. In these meetups, the audience can participate in discussions with experts about the specific topics dealt with in these documentaries, and reflect together with others on their meaning. As research shows, this social aspect of media use-known as 'debriefing' or 'social facilitation,' either online via weblogs or offline in a physical setting — can enrich reflection on the topic and positively affect persuasion or learning (e.g. Raessens 2007; Neys and Jansz 2010; Jacobs 2017). Although Collapsus is a single-player game and meetups in a physical setting had not yet started in 2010, audiences and experts could still meet virtually and exchange ideas via VPRO's weblog, energy.vpro.nl.

Citizenship: Post-liberal and global. Stoknes emphasizes that we must "act as social citizens, not individuals" (2014, 91). Faced with worldwide problems like global warming, pollution, and energy transition, environmental change

6 Collapsus received a Digital Emmy Award for Best Digital Fiction, a People's Choice Award, and Interactive Award nominations at the Dutch Spin Awards, and a World Summit Award for its technical and aesthetic qualities, and its convincing message.

$7 \quad$ VPRO Tegenlicht is a series of informative programes that research new ideas and trends in the world of politics, economy, society, technology, and science. 
can only be envisioned when four conditions are met. First, green citizens, post-liberal politics, and environmental social justice movements need to mutually reinforce each other on a local and global scale. Second, green citizens need to behave pro-environmentally and participate in public debate. Third, post-liberal politics need to regulate markets and industries across borders via more stringent environmental legislation. And fourth, environmental social justice movements need to carry out ecological change on a global scale through group action. Changes in personal attitudes and/ or behavior (think of green lifestyles and ethical consumption) should strengthen socio-political solutions, not replace them (Barendregt and Jaffe 2014; Klein 2014). As we will see in the next section, these four ideas are embodied by Collapsus's characters. Global ecological citizenship is understood as "including the right to a non-polluted environment and the responsibility both to refrain from harming the environment and to participate in its preservation and rehabilitation" (MacGregor 2014, 114).

\section{Unpacking Collapsus}

As I explained earlier, Collapsus consists of three screens or panels contained on one web page (see Figure 5.1). The main fictional storyline is presented in the center panel. In approximately 35 minutes of playing time, you can observe the consequences of the energy crisis in the everyday lives of ten people. The right and left panels light up at certain points in the story. This storyline is designed in such a way that users have to choose their own perspective as the storyline unfolds by participating in three different ways. If you click on the right-hand, documentary panel, you can get a broader perspective by watching CitizEnergy web vlogs-with an average length of two and a half minutes - presented by two characters, Elena and Esperanca. They include comments from other Collapsus characters and short docu-clips where scientific experts provide players with background information. If you click on the left-hand, game panel, you can play simulation games with the goal of avoiding future blackouts. As part of the storyline in the center panel, minigames can be played.

According to Henry Jenkins, "transmedia storytelling is the art of world making. To fully experience any fictional world, consumers must assume the role of hunters and gatherers, chasing down bits of the story across media channels" $(2006,14)$. To be able to reconstruct Collapsus' storyline, a time-consuming task, users indeed have to interactively find ways to move around and inside the game's different elements. Experiencing Collapsus is 
what Katie Salen, Eric Zimmerman, and Miguel Sicart might call a playful activity. To play with Collapsus is to interactively play "with all of these structures [...] finding ways of moving around and inside them" (Salen and Zimmerman 2004, 304). "Play is creative [...] play is the act of creatively engaging with the world [...] to play is to make a world [...] play is a creative, appropriative activity" (Sicart 2014, 17, 73). Depending on the perspective you take, playing Collapsus can thus not only be interpreted as 'gamelike' or 'intermedial' — as I argued above — but also as a 'playful' experience.

On the landing page of the website collapsus.com we recognize the London Eye - the place where the story will start — and are given the possibility to click on the 'enter collapsus' link. When we do so, we see a short introductory clip that gives us a little taste of what is to come; it creates a context for the upcoming experience. We can read the following text: "All over the world energy resources are drying up and the world is blacking out." The text is accompanied by frightening music and worrying images of a woman in the middle of a civil-war-like situation. Later, we will discover that she is the story's main protagonist Vera, vlogging from Tehran, Iran. After the intro the title emerges-Collapsus - Energy Risk Conspiracy. I will present what happens next in four steps. First, I will summarize the thirteen episodes of the fictional storyline and introduce the main characters. I will then present the three ways in which this storyline is completed or annotated, starting with the fifteen documentary news items in the right panel, followed by the six minigames within the center panel; and finishing with the two simulation games to be played in the left panel.

Fictional storyline. Collapsus is a conspiracy thriller about ten, mostly young people, located all over the world and how the worldwide energy crisis affects them. To help us, a world map is shown in the left panel where we can obtain information about the characters and where we can constantly track their locations (see Figure 5.2). In the first episode (1)London»2012; see Table 2) the nine main characters are introduced: Vera, a world citizen and the leading character, who likes to vlog; Marianne, Vera's mother and a member of the European Parliament; Jack, an American oil trader; Elena and Esperanca, founders of the CitizEnergy.org vlog that informs people about the impact of the energy transition; Tony, an environmental activist who resists the economic elite that obstructs the development of new, cleaner forms of energy; Chen, a representative of Tiger NRG, a Chinese energy firm; and Ali and Amir, two Iranian brothers who discuss the energy situation in Iran. In episode (3), Vera gives birth to her daughter, Liana, the tenth main character. Jack is Liana's father. 


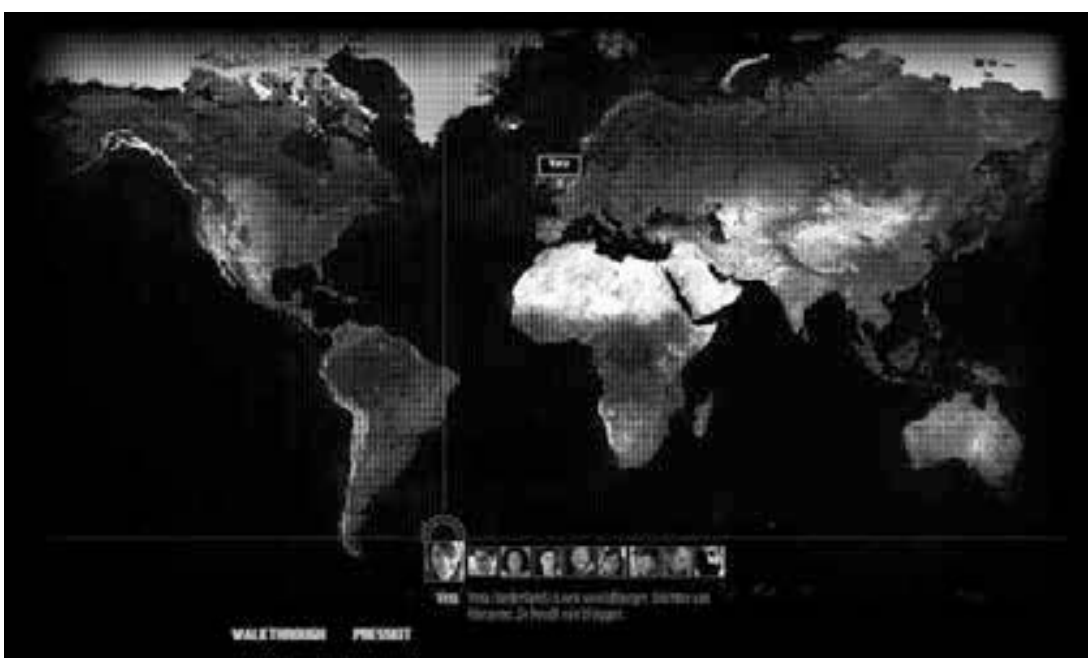

5.2: Collapsus - World map.

At the bottom of the screen we see the storyline, which starts in 2012 and runs, as we discover when the story unfolds, until 2025. The story events take place in six different years, and consist of thirteen main episodes that are explicitly mentioned in the center panel (see the upper two rows in Table 2).

Table 2: Structure of Collapsus

\begin{tabular}{|c|c|c|c|c|c|c|}
\hline Year & 2012 & 2013 & 2015 & 2016 & 2017 & 2025 \\
\hline Episode & $\begin{array}{l}\text { (1)London } \\
\text { " } 2012 \\
\text { (2)London } \\
\text { " } 3 \text { weeks } \\
\text { later }\end{array}$ & $\begin{array}{l}\text { (3) St Thom- } \\
\text { as' Hospital } \\
\text { " } 8 \text { months } \\
\text { later }\end{array}$ & $\begin{array}{l}\text { (4)Sofia, } \\
\text { Bulgaria } \\
\text { " } 2 \text { years } \\
\text { later }\end{array}$ & $\begin{array}{l}\text { (5) Strait of } \\
\text { Hormuz » } \\
\text { Middle East } \\
\text { (6)Tehran, } \\
\text { Iran }\end{array}$ & $\begin{array}{l}\text { (7)Angola, } \\
\text { Africa » } \\
\text { Months later } \\
\text { (8)Riyadh, } \\
\text { Saudi Arabia } \\
\text { "Middle East } \\
\text { (9)Wash- } \\
\text { ington DC » } \\
\text { USA } \\
\text { (10) Boulder, } \\
\text { Colorado } \\
\text { USA » One } \\
\text { month later }\end{array}$ & $\begin{array}{l}\text { (11)Years } \\
\text { later Austin, } \\
\text { Texas » USA } \\
\text { / Beijing, } \\
\text { China } \\
\text { (12)Austin, } \\
\text { Texas » USA } \\
\text { (13)Amster- } \\
\text { dam » The } \\
\text { Netherlands }\end{array}$ \\
\hline $\begin{array}{l}\text { ONews } \\
\text { item/ } \\
\text { ФSim }\end{array}$ & $\begin{array}{l}\text { O०००[Ф०] } \\
\text { O }\end{array}$ & O & [ФО] & 000 & $\mathrm{OO}$ & 0 \\
\hline $\begin{array}{l}\text { Mini- } \\
\text { game }\end{array}$ & (1) 2 & (3) & (4) & 5 & 67 & \\
\hline
\end{tabular}


Following the adventures of the main characters, we are led into a world of failing energy supplies and political and economic powers trying to cope with the transition from fossil fuels to alternative energy sources, while dealing with political dissension, uprisings, and a population terrified by increasingly frequent blackouts. London, for example, is confronted with blackouts and power failures in its energy network(1)(2); a climate conference is organized in Sofia and the energy order discussed(4); terrorists blow up ships in the Strait of Hormuz, a highly strategic location for the international oil trade (5); there is civil war and dictatorship in Iran(6); there are food riots in Angola, and space-based solar power (SBSP) is introduced (7); ideas for a peaceful and productive Middle East are discussed (8); the world is in chaos 9; research is conducted into new energy technologies, such as SBSP(10; we see the demise of the fossil fuel industries, i.e. oil, gas, and coal businesses (11); Tiger NRG executives like Chen are arrested, accused of an energy conspiracy (12); and, finally, there is a multiple screen with several characters reflecting outloud on what they have done up to that point and what their ideas are for the future13.

This portrayal of a worldwide energy crisis, with all kinds of economic, political, and social implications, is an important persuasive dimension of Collapsus and in line with Stoknes' argument that "[t]he solutions to curbing wasteful practices and overconsumption are systemic, large-scale, and societal" (2015, 91). But to get there, as Stoknes also points out, we "need many small-step solutions in the right direction" (Ibid.). The reactions of most of the nine characters to the energy crisis are these kinds of 'smallstep solutions.' The positive values the storyline attaches to them (and the negative values attached to Chen, and Jack to a lesser degree), are crucial in understanding Collapsus's persuasive argument.

The nine characters positions can be understood best based on the five major stages of the stages-of-change model (see Table 3) and the segmentation analysis of Global warming's six Americas (Yale 2016). Merging the models of Slater and Yale helps to analyze how Collapsus 'uses' characters for persuasive purposes.

The first, precontemplation, describes people who have no intention of changing and often no awareness that there may be reasons to consider a behavior change. In the second stage, contemplation, people have recognized that a problem exists and are considering taking action in the not-toodistant future, but have not yet committed themselves to taking action. Preparation is a transitional stage in which people have begun to experiment with or attempt the relevant action and are intending to try the action 
again, but have not yet successfully modified their own behavior. Action represents, then, successful behavior changes for some specified length of time. Maintenance, the final stage, is the ability to sustain the behavioral changes over time (Slater 1999, 337).

Table 3: Stages-of-change model applied to Collapsus

\begin{tabular}{|c|c|c|c|c|c|c|c|}
\hline & & ntemplation & & emplation & Preparation & Action & Maintenance \\
\hline Vera & $x$ & $\longrightarrow$ & $x$ & $\longrightarrow$ & $\longrightarrow$ & $x \longrightarrow$ & $x$ \\
\hline Jack & $x$ & $\longrightarrow$ & $x$ & & & & \\
\hline Tony & & & & & & & $x$ \\
\hline Elena \& & & & & & & & $X[X]$ \\
\hline Esperanca & & & & & & & (Esperanca dies) \\
\hline Chen & $x$ & & & & & & \\
\hline Ali \& Amir & & & & & & & $x x$ \\
\hline Marianne & & & & & & & $\begin{array}{l}{[\mathrm{X}]} \\
\text { (Marianne retires) }\end{array}$ \\
\hline
\end{tabular}

This stages-of-change model can be complemented by the segmentation analysis of Global warming's six Americas (Yale 2016):

The Alarmed are fully convinced of the reality and seriousness of climate change and are already taking individual, consumer, and political action to address it. The Concerned are also convinced that global warming is happening and a serious problem, but have not yet engaged the issue personally. Three other Americas - the Cautious, the Disengaged, and the Doubtful—represent different stages of understanding and acceptance of the problem, and none are actively involved. The final America-the Dismissive are very sure it is not happening and are actively involved as opponents of a national effort to reduce greenhouse emissions. (Yale 2016)

As we can see in Table 3, Vera is the character that passes through every stage. In her first vlog (episode(2)), Vera is reporting on the London blackouts. Like her friends from CitizEnergy, she has a list of dos and don'ts for the next blackout. When the power outage starts, she advises us: "You eat all the ice cream in the freezer, read a book by candlelight, go out on the roof and gaze at the stars, or do the one thing we all do very well in the dark: have sex. Well, that's about all I have to contribute." She is more focused on her own personal problems, in particular being pregnant while the baby's father Jack is not around. And when her mother Marianne tries to explain the energy crisis to her, she answers: "I do not even know what that 
means." She calls it leftish talk; the most important thing for her is being pregnant (precontemplation). In her second phase, Vera visits her mother in Bulgaria(4), where she is attending a conference on climate change. Vera seems to accept her mother's political analysis, but without committing herself to action. Her contemplation is being interrupted by her crying child. A little later, she seems to realize the need to resist when her mother Marianne tries to convince her to join her friends at the CitizEnergy network: "Vera, join them, use your audience, do some real reporting" (contemplation). Vera's vlog about the civil war in Teheran, Iran(6) is her first attempt to do some real reporting. But she is still in doubt about what to do. On the one hand, she wants to stay and join the peaceful protests of the people of Iran; on the other hand, she wants to seek a safe haven and leave the country via Tehran's airport: "I'm almost home, dear Liana" (preparation). Vera's successful behavioral transformation begins when she meets Tony, just as she is getting ready to go back home. Tony asks her to follow him to see the truth(6), that China and the United States are supporting the Khameini regime by delivering weapons (action). Vera's last phase starts when she tries to persuade Jack to share her point of view (6) — "Look around you, Jack. Look deeper. Is this the world you wanna live in? Oil and coal, inefficient, dirty, both limited resources that are bad for the world, bad for people. Do you see where this leads to?" - and ends with her announcement that she will become the new administrative head of the European SBSP program and will stop vlogging13 (maintenance).

Whereas Vera only gradually becomes alarmed about the energy crisis and chooses - in the end — to go for a technological solution (SBSP), six other characters are alarmed from the beginning. They are Elena and Esperanca, Marianne, Tony, and Ali, and Amir. They represent three other strategies - media, political, and activist — for dealing with the energy crisis. Elena and Esperanca are reporting, for example, about the climate change conference in Bulgaria and explaining how the food riots in Angola are caused by the energy crisis. While Esperanca dies in Angola, Elena continues this important work. Their vlogs can be seen in the right-hand panel of Collapsus - I will return to this later. Marianne's political career is shown from the beginning (her election as a member of the EU parliament) up to the end when she retires. She visits a climate change conference and explains her position to Vera: "The UK is falling behind, the infrastructure is laughable. What will they do? Allow themselves to be held hostage by Russia? As if foreign fuel is any kind of solution. You can trust the wind, you cannot trust Russia." And when Vera answers that she does not understand this, Marianne continues: “It means: why don't they diversify their sources 
of electricity: wind, nuclear, solar. Why don't they build storage facilities?" Tony, an environmental activist, is the first character we meet; his first statement sets the tone: "Do not believe the lies. Whose lies? The lies of the corporations who manipulate prices, and the countries that oppose alternative energies so that their resources are getting exploited and their pockets get fat." Tony uses the metaphor of a game and play to explain the energy crisis. According to him, these corporations and countries are strategic players within a worldwide arena (Duyvendak and Jasper 2016). They "game the system," manipulating and exploiting the current energy crisis to their own advantage: "Everybody's a player, it's a big game for them and no one is innocent. The name of the game: the free energy suppression and ecological devastation." At first sight, as Tony admits himself, people often see him as a crazy conspiracy theorist. But what he basically wants is not so illogical. When he meets Vera, he says: "You [Vera] want the truth, like I do. That's why I am here. I want the world to see, to really see. Follow me and I will show you the truth." Three elements of the story show that he is right: the subtitle of Collapsus, 'Energy risk conspiracy'; his discovery that China is indeed delivering weapons to Iran; and his disclosure of secret documents - framed as an act of civil disobedience-(in the 'Unlock the vault' minigame) that proves that there is a conspiracy between individuals within the coal, gas, and oil industry. Ali and Amir are working toward a peaceful and productive Iran, or even the entire Middle East, avoiding two extreme positions, i.e. people representing the Iranian government and oil interests, and people who want to use violence against the government.

Chen and Jack represent the other end of the spectrum. Chen is the archetypal bad guy, he is dismissive and shows no intention of taking climate change seriously. He blackmails Jack to join him at Tiger Energy (NRG), and is exposed and arrested in the end. Initially, Jack also defends the oil business ("Oil is cheap, it's versatile, oil built the 2oth century," in his conversation with Vera), but he is realistic enough to change his position from dismissive to doubtful: "The [oil, coal] business is gone to hell, Chen." Jack also suggests that Vera should meet the representative of SBSP, David Peng. However, Jack is not committed to taking action himself: in the last episode, he is at home, taking care of Liana.

Collapsus ends with a multiple screen showing competing voices and images, with Vera in the center screen (see Figure 5.3). This is in line with Stoknes' argument that a plurality of stories is needed. Vera reflects on the energy transition ("It will be a rough transition, with heavy costs on all sides; and who's to say it's a transition we can manage") and announces her new job and her decision to stop vlogging: "Others will still do the work," 


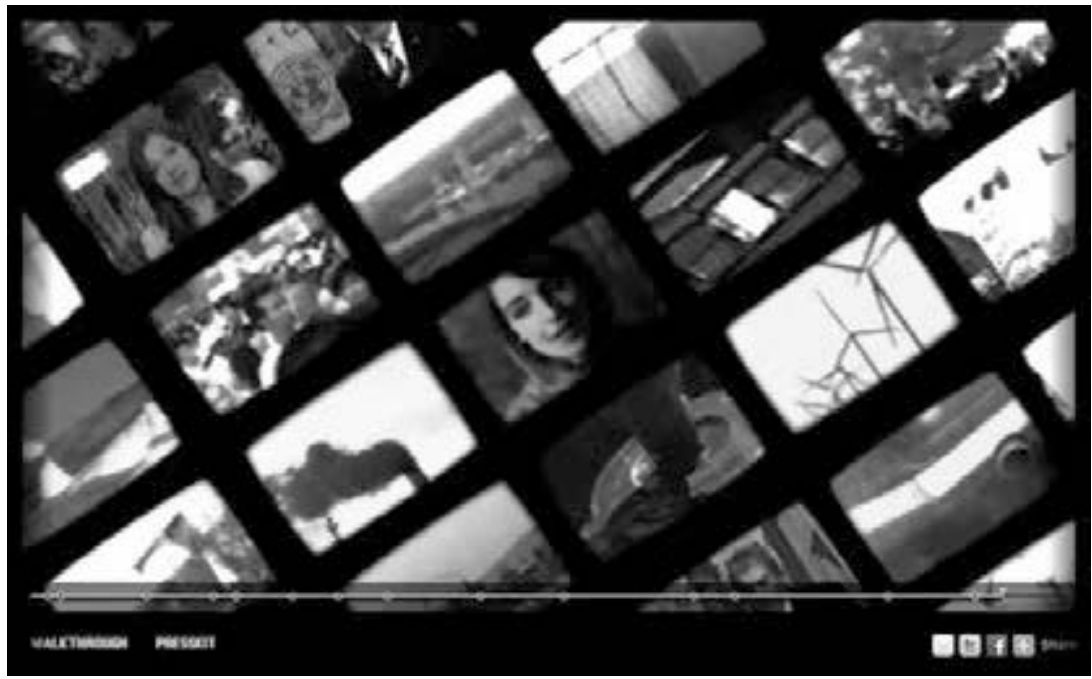

5.3: Collapsus - Multiple screens.

she recounts, "and you should listen to them. Elena and the others know that we are not out of the woods yet." Marianne retires from politics ("It's time to let others take my place. I did not see how complex the world was when I first began this"), Elena continues vlogging ("We must always have a voice"), Ali and Amir are on the run ("We know things. Things about our old masters that will shine a light in dark places. It will be dangerous, but we must strive to reveal the truth"), Tony continues with his activist work ("I have tried to make a difference, I think I did, but at what cost? I have to keep trying, I have to"), and Chen tries to arrange a deal with the police to get out of prison ("I will sell everybody off, I'll be safe, I'm always safe"). These reflections on what happened in Collapsus are forms of 'interpassive feedback' (Pfaller 1999). This last episode provides the player with possible interpretations of the actions of the main characters; this media production is designed in such a way that it provides for its own reception. Even so, ultimately, it is up to the individual players to come up with possible interpretations.

Documentary news items. The fictional storyline is complemented by fourteen CitizEnergy news reports that pop-up at certain points in the storyline (see Table 2, row 3: 'O'). The first one, for example, pops up right after Tony's initial statement: "Do not believe the lies" (see Figure 5.4). We see the CitizEnergy logo, a world map with-in red-the place where the vlog comes from (in this case, London), the name of the vlogger (in 


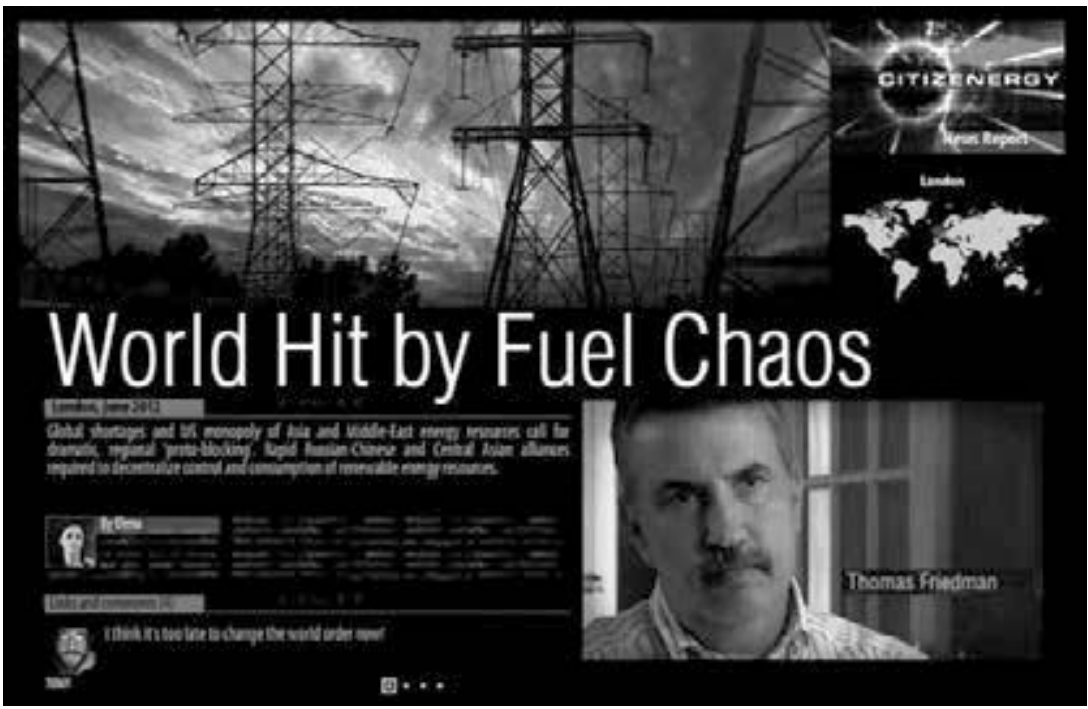

5.4: Collapsus - CitizEnergy news report.

this case, Elena) and a short text: "London, June 2012. World Hit by Fuel Chaos. Global shortages and United States monopoly of Asia and Middle East energy resources call for dramatic, regional 'proto-blocking.' Rapid Russian-Chinese and Central Asian alliances required to decentralize control and consumption of renewable energy resources." There are comments from the main characters, in this case Tony, Jack, and Esperanca, and a link to the Tegenlicht website. In the bottom right, we see a short documentary video clip with highlights from the VPRO Tegenlicht documentaries on energy that were broadcast on television. In the first news report, for example, we hear about America's addiction to oil, the Iranian interest in destabilizing oil regions to keep prices high, China's strategic need for energy supplies, and the difficulties of initiating reform. The news reports provide a solid basis for the stories and the urgency of the Collapsus characters' changing their behavior. Some examples include Tony's claim that countries and companies manipulate prices and oppose sustainable technologies out of self-interest, and Vera's progression from unconcerned to alarmed.

Collapsus is part of a long-term VPRO Tegenlicht documentary project on the imminent energy transition and the geopolitical energy wars caused by this transition. The three-part project took off in 2006 with a weblog and two television programs: Energy War, Part I. The New Owners of the World, and Part II. The Green Race. These programs portray the West as addicted 
to oil and gas, which are often imported from unreliable petro-capitalist, authoritarian states with a questionable reputation with regard to democracy and human rights. Countries such as Russia, Iran, and Venezuela use their energy supplies as a political weapon to defend their strategic interests. Only by developing new green technologies or green power, such as solar power, wind power, and biofuels, can the West diminish its dependency on these countries and, at the same time, stop destroying our planet and improve our environment. In 2008, VPRO Tegenlicht made an update, Energy War. Plenty of Energy. In this second part of the project, our dependence on fossil fuels is characterized, again, as being highly problematic. The greenhouse effect, rogue oil states, the reduction of world oil production and simultaneous increase in the demand for energy, and uncontrollable, fluctuating prices contribute to a common feeling of crisis. Tegenlicht raises the question of whether we can manage to adopt a new, green energy regime in time using alternative energy sources such as solar power, or whether we will lose this race against the clock.

The last part of this trilogy consists of a television program, Energy Risk, and the game Collapsus, both made in 2010. In Energy Risk (broadcast on 22 March 2010), two alarming future scenarios are presented to a panel of foreign experts in order to assess what kind of geopolitical conflicts Europe might end up in. In the first scenario, Russia abruptly and completely cuts off the gas supply to Europe because of a gas boycott in Uzbekistan. It becomes clear that Europe is too dependent on Russian gas, and, because of that dependency, too reliant on Russia's foreign policy. In the second scenario, the oil supply from the Middle East to the West is stopped unexpectedly by Iranian movements in the Strait of Hormuz. Iran can raise oil prices by destabilizing the region. The West is confronted with enormous oil shortages and the United States therefore decides to intervene militarily, but meets with opposition from China and Russia. Both scenarios demonstrate how geopolitical conflicts about remaining fossil fuels can potentially affect Europe, Europe's increasing vulnerability, and the necessity to switch more rapidly to alternative sources of energy. Collapsus was officially launched at the end of the Energy Risk program with a presentation of its trailer. ${ }^{8}$

8 Energy Risk was watched by 214,000 viewers. In the first three months, Collapsus.com had 200,000 unique visitors, 25 per cent from the Netherlands, 20 per cent from the United States, 10 per cent each from France and Germany, and 5 per cent from the UK (these statistics date from June 2010; information from VPRO Tegenlicht and Submarine). 


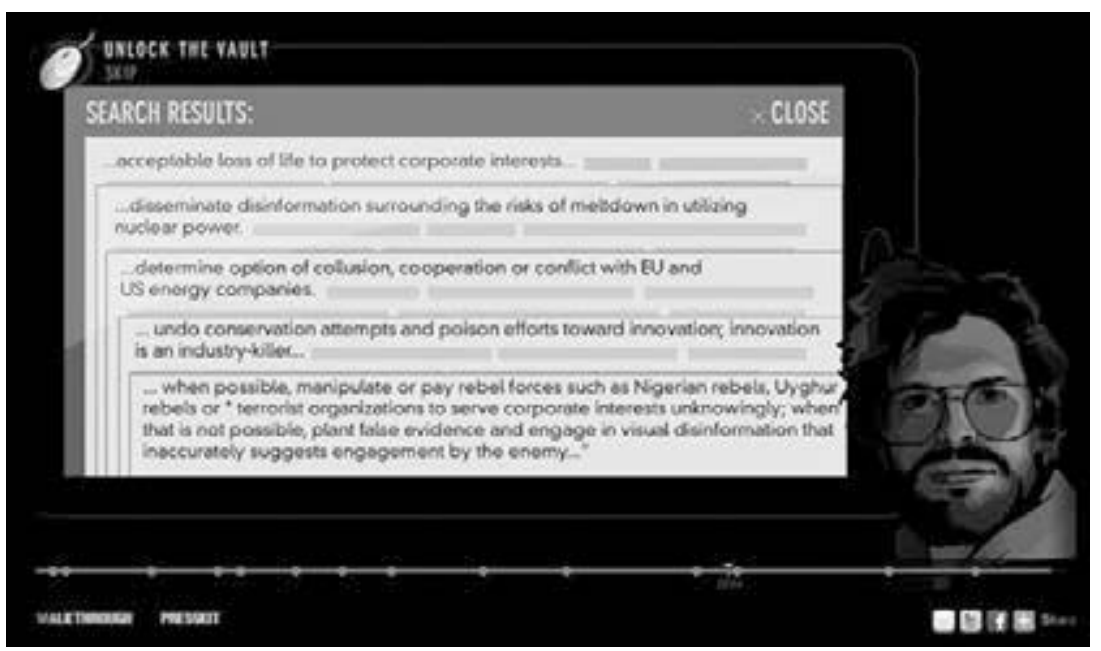

5.5: Collapsus - Tony unlocking the vault.

Minigames. The seven minigames play a small, yet important role in Collapsus (see Table 2, row 4). Three of them are related to Tony's effort to reveal some secret information. In the first minigame, the player has to move the cursor to reveal a message from Tony. If you fail or skip this game, you cannot read Tony's message: "I'm on the inside now [...] I trust you know what to do with this." In the sixth minigame, the player has to unlock the vault: "Head office filepad: Passkey protected. Slide to unlock," we can read on the screen. If you fail or skip this game, you cannot read the shocking documents Tony hands over to Vera later on, which will lead to the arrest of the Tiger NRG's representatives (see Figure 5.5).

In the seventh minigame, you have to move the cursor to reveal the following text: "We will use this info to destroy the puppet masters at any cost." If you fail or skip this minigame, you do not know that Tony is about to expose Tiger NRG's representatives. In two other minigames, the player has to tune into a conversation. If you fail or skip the fourth one, you miss a crucial point where Marianne convinces Vera to do some real reporting. If you fail or skip the fifth one, you cannot understand the relationship between the two brothers Amir and Ali. The second and third minigames do not play an important role.

Simulation games. In the second and fourth episodes, a binary choice pops up for the player (see Table 2, row 3 ) to see a news item $(\mathrm{O})$ or to play a short-session sim game $(\Phi)$. Sim games are games that simulate aspects of reality relying on rule-based interactions as their core mode of signification. 


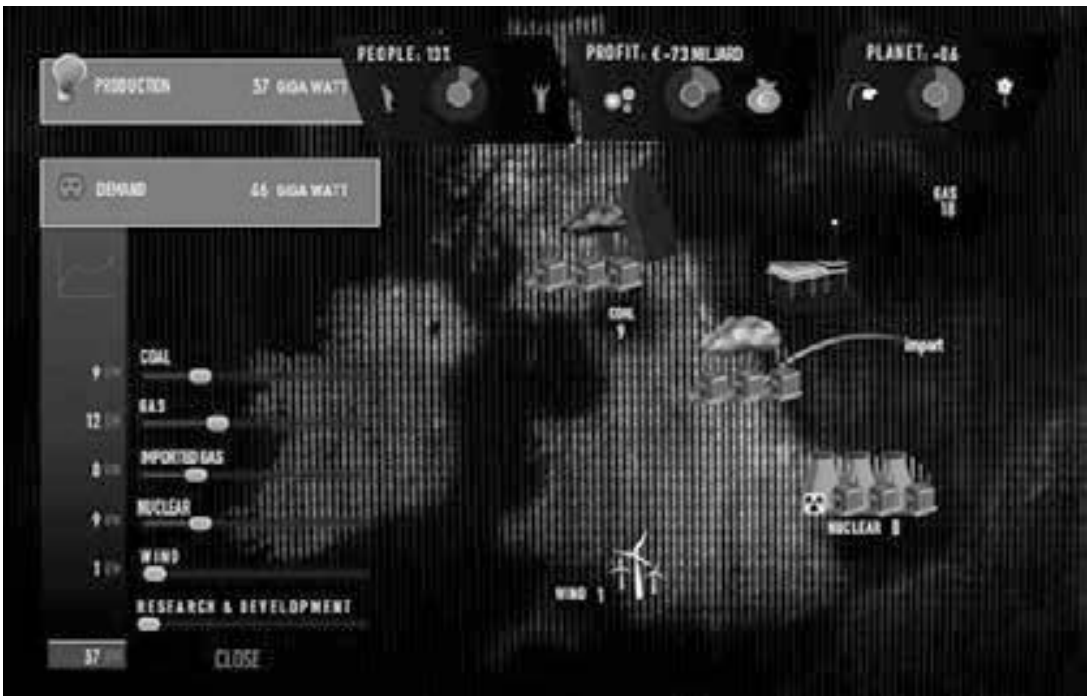

5.6: Collapsus - Playing field.

The player has to carry out two simple assignments. ${ }^{9}$ The first time a binary choice pops up for the player, it is under the label 'Blackouts.' The news item in the right panel 'London: New Blackout Panic' deals with our energy dependency and how to deal with such a blackout. If you click on the left panel, you see a world map with Great Britain in red and London flickering. If you move your cursor to Britain, the following text pops up: "London-Avoid the blackouts. The UK has lowered its energy production using coal and nuclear energy by 30\%. Demand has risen. Avoid the blackouts. Choose wisely!" If you click again, the playing field pops up (see Figure 5.6). ${ }^{10}$

You see that energy production (37 gigawatt) falls short of the demand for energy (46 gigawatt). The game has a simple goal: you have to produce more energy to meet the demand, making a choice between several energy sources (coal, gas, imported gas, nuclear, and wind) while keeping a harmonious balance between the three Ps: People, Profit, and Planet. The three Ps incorporate social, economic, and ecological dimensions that measure and

9 I will only analyze the first sim game. The second sim game deals with the gas crisis in Bulgaria, after Russia decided to cut the gas supplies. The goal of this sim game is to find alternative energy resources. The conclusion is that wood is better than coal, while oil is the worst choice.

10 As part of the British government's goal to improve the environment, they decided to generate less electricity from coal and nuclear fuel. Because of global warming, the use of air conditioning has exploded, which leads to an increase in demand (information from Submarine). 
evaluate the impact of an organization's activities on the world-in this first game the impact of augmenting energy production in the UK.

The basic rule of the game-according to Bogost's procedural rhetoric, the most important element of a game's meaning - is an ideologically motivated one: players can win the game by choosing a specific energy source, or a combination of sources that meet the energy demand while keeping the impact on the Planet as low as possible. Coal turns out to be the worst choice, then gas, then nuclear, while wind is the best. I can demonstrate that this is the case by selecting five different actions and seeing what their impact is on the three Ps (Table 4).

Table 4: Impact of different energy sources

\begin{tabular}{|c|c|c|c|c|c|c|c|}
\hline Source & $\begin{array}{l}\text { Giga- } \\
\text { watt }\end{array}$ & People & $\begin{array}{l}\text { Impact on } \\
\text { People }\end{array}$ & Profit & $\begin{array}{l}\text { Impact on } \\
\text { Profit }\end{array}$ & Planet & $\begin{array}{l}\text { Impact on } \\
\text { Planet }\end{array}$ \\
\hline \multirow[t]{2}{*}{ Coal } & 9 & $13 \%$ & $+27 / 6=+4.5$ & $\begin{array}{l}-7.3 \\
\text { billion }\end{array}$ & $+4.8 / 6=+0.8$ & -0.6 & $-1.3 / 6=-0.22$ \\
\hline & $+6(15)$ & $40 \%$ & & $\begin{array}{l}-2.5 \\
\text { billion }\end{array}$ & & -1.9 & \\
\hline \multirow[t]{2}{*}{ Gas } & 12 & $13 \%$ & $+61 / 11=+5.55$ & $\begin{array}{l}-7.3 \\
\text { billion }\end{array}$ & $+8.2 / 11=+0.75$ & -0.6 & $-1.4 / 11=-0.13$ \\
\hline & $+3(15)$ & $27 \%$ & & $\begin{array}{l}-6.0 \\
\text { billion }\end{array}$ & & -1.0 & \\
\hline $\begin{array}{l}\text { Im- } \\
\text { ported }\end{array}$ & 8 & $13 \%$ & & $\begin{array}{l}-7.3 \\
\text { billion }\end{array}$ & & -0.6 & \\
\hline gas & $+8(16)$ & $60 \%$ & & $\begin{array}{l}-0.4 \\
\text { billion }\end{array}$ & & -1.6 & \\
\hline \multirow[t]{2}{*}{ Nuclear } & 9 & $13 \%$ & $+33 / 6=+5.5$ & $\begin{array}{l}-7.3 \\
\text { billion }\end{array}$ & $+5.2 / 6=+0.87$ & -0.6 & $-0.2 / 6=-0.03$ \\
\hline & $+6(15)$ & $46 \%$ & & $\begin{array}{l}-2.1 \\
\text { billion }\end{array}$ & & -0.8 & \\
\hline \multirow[t]{2}{*}{ Wind } & 1 & $13 \%$ & $+9 / 2=+4.5$ & $\begin{array}{l}-7.3 \\
\text { billion }\end{array}$ & $+1.2 / 2=+0.6$ & -0.6 & $0.0 / 2=0.0$ \\
\hline & $+2(3)$ & $22 \%$ & & $\begin{array}{l}-6.1 \\
\text { billion }\end{array}$ & & -0.6 & \\
\hline
\end{tabular}

In the black cells, we see the initial state that was recorded. The People have a satisfaction rate of 13 per cent, the Profit is -7.3 billion euro and the Planet has a score of -o.6. Then, we increase the different energy sources to try to meet the demand: we increase coal from 9 to $15(+6)$, gas from 12 to 15 $(+3)$, imported gas from 8 to $16(+8)$, nuclear from 9 to $15(+6)$, and wind from 1 to $3(+2)$. In each case, this is the most that you can do with one energy source in the short term. When you have reached the maximum for coal, imported gas, nuclear energy, and wind, a pop-up tells you: "To produce more, you need 
an extra plant. It takes two years to build one. Do you want to, yes or no?" With gas you get the message: "You can't produce more gas than you do." For every extra gigawatt of energy, Table 4 shows its impact on the three Ps:

- On the Planet: The impact of wind is 0.0 (0.0/2), nuclear is -0.03 $(-0.2 / 6)$, gas is $-0.13(-1.4 / 11)$ and coal is $-0.22(-1.3 / 6)$. Conclusion: coal and gas have more of a negative impact than nuclear energy; wind is neutral. This supports the idea that electricity generated by wind turbines will not pollute the planet in the way that other energy sources do.

- On Profit: The impact of wind is $+0.6(+1.2 / 2)$, nuclear is $+0.87(+5.2 / 6)$, gas is $+0.75(+8.2 / 11)$, coal is $+0.8(+4.8 / 6)$. Conclusion: the positive impact of wind is only slightly less than that of coal, gas, and nuclear energy. This supports the idea that wind energy is not as expensive as it is assumed to be.

- On People: The impact of wind is $=+4.5(+9 / 2)$, nuclear is $+5 \cdot 5(+33 / 6)$, gas is $+5 \cdot 55(+61 / 11)$, coal is $+4 \cdot 5(+27 / 6)$. Conclusion: the positive impact of wind is comparable to that of coal, nuclear energy and gas. This supports the idea that wind is indeed the best solution.

This conclusion also makes clear that a focus on Collapsus's 'rule-based' procedural rhetoric alone is not enough to understand its meaning. In the Netherlands, for example, few environmentally minded people accept nuclear power as a serious alternative (SCP 2016) and they would probably oppose any positive reference to nuclear power if they were to play Collapsus.

A player can gain two important insights by playing this sim game. The first insight is a general one and in line with Marshall McLuhan's idea that the medium itself can persuade us, rather than the specific message it conveys (Dobrin and Morey 2009, 257-277). In playing the game, the user is actually experiencing the difficulty of harmoniously balancing the three Ps; the dilemmas and consequences of making choices become clear. The second insight is more precise and related to specific implicit or explicit environmental messages incorporated into the game design. As I showed in my analysis, this sim game privileges as an outcome investment in sustainable energy such as wind, rather than nuclear energy, gas, and coal - at least, if the player takes the impact on the Planet as the main criterion. Another player might privilege Profit, in which case nuclear energy, coal, and gas would still be a better choice than wind. We learn that diversification of energy resources - especially in the first two years - is necessary because it takes time to build new power stations and develop new, experimental solutions like space-based solar power. Wind energy only is not a solution. 


\section{Conclusion}

In this chapter, I have analyzed how Collapsus uses a set of rhetorical strategies to engage individual citizens in climate issues. Collapsus is only one example (older, but still timely) of a growing number of ecological games that can serve as effective tools for promoting attitude change, proenvironmental behavior, and a better understanding of the complexity of the issues around climate change (Raessens 2017, 2018). Textual analyses like this chapter allow us to better understand individual productions like Collapsus, providing insight into its construction and socio-cultural relevance. According to many researchers, there is growing evidence on the effectiveness of games as a medium for persuasive communication (Neys and Jansz 2010; De Grove et al. 2012; Ruggiero 2015; Jacobs 2016, 2017; Jacobs, Jansz, and De la Hera 2017). This kind of validation research could help in the design of better games, and in determining the conditions that would help actualize the 'civic potential' from playing these games and help turn players into ecological citizens (Kahne et al. 2009). ${ }^{11}$

Research into the persuasiveness of media must allow for the fact that it is not always easy and straightforward to determine what exactly the intended message is. In relation to Collapsus, two kinds of limitations are of importance. First, the design process was characterized by pragmatic limitations. Because of financial and time restrictions, the designers of $\mathrm{Col}-$ lapsus needed to limit the number of variables in the sim game I discussed. To solve the problem of rising energy demands, the player can only try to increase energy production. Lowering the demand via energy-savings-a logical variable - is not an option. Second, realistic future scenarios had to be designed within the framework of existing generic conventions and the limitations of the narrative economy. The conventions of a conspiracy thriller for example, require that the complexities of a historical situation-such as energy transition - are simplified in a kind of morality play in which bad characters (such as Chen and, to a lesser degree, Jack) embody bad behavior, and good people (such as Tony and Vera, unraveling the conspiracy) defeat them in the end. And for reasons of narrative economy, Vera's politicization and personal growth from 'dismissive' to 'alarmed,' and from 'precontemplation' to 'maintenance' occur in short, simplified stages-of-change. The optimistic end she proclaims might also be misleading.

11 In our research project Persuasive gaming. From theory-based design to validation and back, we try to integrate these three research strands of analysis, design, and validation, see NWO (2018) and PGiC (2018). 
She announces, "who can say what the future will bring? Well, me! I will be the new administrative head of the European SBSP programme." The intended message is that Vera will stop vlogging and start doing something more significant in the world. The game designers revealed to me in a conversation, that the technical solution Vera seems to embody (SBSP) is of minor importance for the storyline.

Environmental issues pose formidable imaginative and political difficulties for media producers. Collapsus tries to solve this by designing a story in which realistic energy transition scenarios are being described that are personal and urgent, having a direct impact on the characters from 2012 through to 2025. Collapsus shows different possible answers to the energy crisis, embodied in the beliefs, values, attitudes, and behavior of the different characters. By being in line with different sets of values and their possible stages-of-change, it can connect with, and possibly persuade, different groups of players. When we look at the strategies for raising awareness that I presented in section 2 , we can conclude that $\mathrm{Col}$ lapsus frames energy transition in a progressive and optimistic way so we can come up with solutions by developing empathy and responsibility, and that it uses different media (narratives, documentaries and games) and social networks to persuade its players to adopt a post-liberal and global form of citizenship. Collapsus is one possible answer to a question posed by Nixon: "How can we turn the long emergencies of slow violence into stories dramatic enough to rouse public sentiment and warrant political intervention?" $(2011,3)$. Because of its playful combination of a fictional storyline, documentary, and games, Collapsus was able to draw the attention of a large group of people, who were younger than the normal audience for documentaries, to the subject of climate change. Collapsus embodies what Henry Jenkins describes as 'civic imagination.' It shows the ability of a network of political agents (green citizens, politicians, activists, and vloggers) to imagine both a future world and how to turn this world into a better one (Jenkins et al. 2016, 152).

\section{Acknowledgments}

This research is part of the project Persuasive gaming. From theory-based design to validation and back, funded by the Netherlands Organisation for Scientific Research (NWO; 2013-2018; project number 314-99-106). I would like to thank Karel Brascamp and Christiaan de Rooij (Submarine), and Nina Huisman and William de Bruijn (VPRO Tegenlicht) for providing me 
with illustrations and background information on Collapsus and Energy Risk. I would also like to thank Jeroen Jansz, Teresa de la Hera, and Ruud Jacobs for their helpful and constructive comments on an earlier version of this chapter.

\section{References}

Barendregt, B., and R. Jaffe. 2014. Green consumption. The global rise of eco-chic. London: Bloomsbury.

Bogost, I. 2007. Persuasive games. The expressive power of videogames. Cambridge, MA: The MIT Press.

De Crom, A. 2010. Trendsetter van de toekomst. Skrien 3:8-13.

De Grove, F., J. van Looy, J. Neys, and J. Jansz. 2012. Playing in school or at home? An exploration of the effects of context on educational game experience. Electronic Journal of E-Learning 10 (2): 199-208.

Dobrin, S. I., and S. Morey, eds. 2009. Ecosee:Image, rhetoric, nature. Albany, NY: State University of New York Press.

Duyvendak, J. W., and J. M. Jasper. 2016. Players and arenas: The interactive dynamics of protest. Amsterdam: Amsterdam University Press.

Flanagan, M., and H. Nissenbaum. 2014. Values at play in digital games. Cambridge, MA: The MIT Press.

G4C. 2018. About us: Games for change. Games for Change. http://www. gamesforchange.org/about.

Green, M. C., and K. M. Jenkins. 2014. Interactive narratives: Processes and outcomes in user-directed stories. Journal of Communication 64 (3): 479-500.

Guggenheim, D. (dir.) 2006. An Inconvenient Truth. Paramount Pictures. Film. Ingram, D. 2000. Green screen: Environmentalism and Hollywood cinema. Exeter: University of Exeter Press.

Jacobs, R. S. 2016. Play to win over: Effects of persuasive games. Psychology of Popular Media Culture. http://psycnet.apa.org/doi/10.1037/ppmooo0124.

- 2017. Playing to win over: Validating persuasive games. $\mathrm{PhD}$ thesis: Erasmus University Rotterdam.

Jacobs, R. S., J. Jansz, and T. de la Hera. 2017. The key features of persuasive games: A model and case analysis. In New perspectives on the social aspects of digital gaming: Multiplayer 2, eds. R. Kowert and T. Quandt, 153-171. New York: Routledge.

Jansz, J. 2016. Serious gaming. MOOC Erasmus University Rotterdam, Netherlands. http://www.coursera.org/learn/serious-gaming. 
Jenkins, H. 2006. Convergence culture. Where old and new media collide. New York: New York University Press.

Jenkins, H., M. Ito, and d. boyd. 2016. Participatory culture in a networked era. Malden, MA: Polity Press.

Kahne, J., E. Middaugh, and C. Evans. 2009. The civic potential of video games. Cambridge, MA: The MIT Press.

Kattenbelt, C. 2008. Intermediality in theatre and performance: Definitions, perceptions, and medial relationships. Cultural Studies Journal of Universitat Jaume I 6:19-29.

Killingsworth, M. J., and J. S. Palmer. 1992. Ecospeak: Rhetoric and environmental politics in America. Carbondale, CO and Edwardsville, IL: Southern Illinois University Press.

Klein, N. 2014. This changes everything: Capitalism vs. the climate. New York: Simon \& Schuster.

Lakoff, G. 2010. Why it matters how we frame the environment. Environmental Communication 4 (1): 70-81.

Lewis, A. (dir.) 2015. This Changes Everything. Bertha Foundation. Film.

MacGregor, S. 2014. Ecological citizenship. In Handbook of political citizenship and social movements, ed. H.-A. van der Heijden, 107-132. Cheltenham: Edward Elgar Publishing.

Neys, J., and J. Jansz. 2010. Political internet games: Engaging an audience. European Journal of Communication 25 (3): 227-241.

Nixon, R. 2011. Slow violence and the environmentalism of the poor. Cambridge, MA: Harvard University Press.

NWO. 2018. Persuasive gaming. From theory-based design to validation and back. NWO. http://www.nwo.nl/onderzoek-en-resultaten/ onderzoeksprojecten/i/76/10476.html.

Pallotta, T. 2010. Collapsus - Energy Risk Conspiracy [browser]. Submarine Channel. Game.

Pfaller, R., ed. 1999. Interpassivität: Studien über delegiertes Genießen. Vienna: Springer.

PGiC. 2018. Persuasive gaming in context: From theory-based design to validation and back. Persuasive Gaming in Context. http://www.persuasivegaming.nl.

Popper, K. 1999. All life is problem solving. New York: Routledge.

Raessens, J. 2006. Reality play: Documentary computer games beyond fact and fiction. Popular Communication 4 (3): 213-224.

-. 2007. Playing history: Reflections on mobile and location-based learning. In Didactics of microlearning. Concepts, discourses and examples, ed. T. Hug, 200-217. Münster: Waxmann. 
- 2015. Playful identity politics: How refugee games affect the player's identity. In Playful identities: The ludification of digital media cultures, eds. V. Frissen, S. Lammes, M. de Lange, J. de Mul, and J. Raessens, 245-26o. Amsterdam: Amsterdam University Press.

-. 2017. Gamen om de planeet te redden. De Helling 2:62-65.

- 2018. Ecogames: Playing to save the planet. In Cultural sustainability. Perspectives from the humanities and social sciences, eds. T. Meireis, and G. Rippl, 232-245. London: Routledge.

Renov, M. 1993. Towards a poetics of documentary. In Theorizing documentary, ed. M. Renov, 12-36. New York: Routledge.

Ruggiero, D. 2015. The effect of playing a persuasive game on attitude and affective learning. Computers in Human Behavior 45:213-221.

Salen, K., and E. Zimmerman. 2004. Rules of play: Game design fundamentals. Cambridge, MA: The MIT Press.

SCP (The Netherlands Institute for Social Research). 2016. Burgerperspectieven 4. http://www.scp.nl/Publicaties/Alle_publicaties/Publicaties_2016/ Burgerperspectieven_2016_4.

Sicart, M. 2011. Against procedurality. Game Studies 11 (3). http://gamestudies. org/1103/articles/sicart_ap.

-. 2014. Playmatters. Cambridge, MA: The MIT Press.

Slater, M. D. 1999. Integrating application of media effects, persuasion, and behavior change theories to communication campaigns: A stages-ofchange framework. Health Communication 11 (4): 335-354.

-. 2002. Entertainment education and the persuasive impact of narratives. In Narrative impact. Social and cognitive foundations, eds. M. C. Green, J. J. Strange, and T. C. Brock. 157-181. New York: Psychology Press.

Stoknes, P. E. 2015. What we think about when we try not to think about global warming. Toward a new psychology of climate action. White River Junction: Chelsea Green Publishing.

Sutton-Smith, B. 1997. The ambiguity of play. Cambridge, MA: Harvard University Press.

Turkle, S. 1996. Life on the screen. Identity in the age of the internet. London: Weidenfeld and Nicolson.

Yale Program on Climate Change Communication. 2016. Global warming's six Americas. climatecommunication.yale.edu/about/projects/ global-warmings-six-americas. 
About the author

Joost Raessens is chair and Full Professor of Media Theory at Utrecht University, and scientific director of the Utrecht Center for Game Research (gameresearch.nl). His research concerns the ludification of culture,' focusing on games for change in relation to global climate change and refugee and migration issues. Raessens was conference chair of the first DiGRA conference Level Up in Utrecht (digra2003.org) and leads the research project Persuasive gaming. From theory-based design to validation and back (persuasivegaming.nl). Among his book publications (see raessens.nl for a complete overview) are the Handbook of computer game studies (The MIT Press 2005), Homo ludens 2.0: The ludic turn in media theory (Utrecht University 2012), and Playful identities: The ludification of digital media cultures (Amsterdam University Press 2015). 